Гусейнов М.Ш., Гусейнова С.К. Легкая промышленность Дагестана накануне Великой Отечественной войны (1938-1941 гг.)

\title{
ИСТОРИЯ
}

\section{УДК 967}

DOI: $10.21779 / 2542-0313-2019-34-2-7-13$

\section{М.Н. Гусейнов ${ }^{1}$, С.К. Гусейнова ${ }^{2}$}

\section{Легкая промышленность Дагестана накануне Великой Отечественной войны (1938-1941 гг.)}

${ }^{1}$ Дагестанский государственный университет; Россия, 367001, г. Махачкала, ул. М. Гаджиева, 43a; dekanif@mail.ru;

${ }^{2}$ МБОУ СОШ № 10 2. Махачкаль; Россия, г. Махачкала, ул. Ю. Акаева, 69; ege200610@yandex.ru

Статья посвящена неоценимой помощи народов Российской Федерации и других народов СССР в развитии новых отраслей легкой промышленности Дагестана накануне Великой Отечественной войны. Значительная работа была проведена по коренизации рабочих и ИТР, привлечению горянок в легкую промышленность, механизации предприятий, улучшению социальнобытовых условий работников отрасли.

Предприятия легкой промышленности республики из года в год улучшали показатели по выпуску продукции, и их качеству. В работе предприятий имелся и ряд недостатков, в том числе частая смена директоров и инженерно-технического персонала. В рассматриваемый период наблюдался рост зарплаты рабочих, ИТР и служащих. Накануне войны трудовые коллективы предприятий отрасли Дагестана достигли высоких результатов.

Ключевые слова: Российская Федераиия, Дагестан, наркомат, легкая промышленность, Великая Отечественная война, планирование.

Советское правительство придавало большое значение развитию легкой промышленности. Уже в конце Гражданской войны крупнейшее предприятие легкой промышленности Дагестана - текстильная фабрика «Каспийская мануфактура» - было национализировано и восстановлено. За короткое время предприятие было капитально отремонтировано.

В первые пятилетки в Дагестане появились новые отрасли легкой промышленности - обувная, хлопкоочистительная, швейная. В 1937 году легкая промышленность Дагестана выполнила плановое задание в неизменных ценах 1926/27 года на сумму 9885,4 тыс. руб. (план - 8 839,8 тыс. руб.), или на 1 045,6 руб. (11,8 \%). Продукция предприятий легкой промышленности возросла по сравнению с 1936 г. в ценах 1926/27 года на сумму 1 514,7 тыс. руб.

По отдельным отраслям этот рост выражается в сумме:

- по швейной - 523,4 тыс. руб.

- по кожобувной - 474,8 тыс. руб.

- по шерстопрядильной - 385, 5 тыс. руб.

- по хлопчатобумажной - 131,0 тыс. руб. [1, л. 12].

Но наряду с предприятиями, выполнившими план, крупнейшее предприятие хлопчатобумажная фабрика им. III Интернационала, бывшая «Каспийская мануфактура», годовой план выполнила на 88,4 \%, т. е. недодала государству продукции на сумму 
Гусейнов М.Ш., Гусейнова С.К. Легкая промышленность Дагестана накануне Великой Отечественной войны (1938-1941 гг.)

543 тыс. руб. Это было связано с частыми простоями оборудования, его изношенностью, а также со слабым вовлечением в производство представителей коренных народов. На 1 января 1938 года на предприятии работало 1503 ИТР и рабочих из коренных народностей, в том числе рабочих - 787 чел.

Таблица 1 [1]

\begin{tabular}{|c|c|c|c|c|c|c|}
\hline \multirow[t]{2}{*}{ Предприятия } & \multicolumn{2}{|c|}{$\begin{array}{c}\text { Численность } \\
\text { персонала }\end{array}$} & \multicolumn{2}{|c|}{$\begin{array}{c}\text { Коренной } \\
\text { национальности }\end{array}$} & \multicolumn{2}{|c|}{$\begin{array}{c}\text { \% коренной } \\
\text { национальности }\end{array}$} \\
\hline & Всего & $\begin{array}{l}\text { В том числе } \\
\text { рабочих }\end{array}$ & Всего & $\begin{array}{c}\text { В том числе } \\
\text { рабочих }\end{array}$ & Всего & $\begin{array}{c}\text { В том числе } \\
\text { рабочих }\end{array}$ \\
\hline $\begin{array}{l}\text { Фабрика им. } \\
\text { III Интерна- } \\
\text { ционала }\end{array}$ & 1873 & $\begin{array}{c}1139 \\
60,8 \%\end{array}$ & 886 & 422 & 47,3 & 37,0 \\
\hline $\begin{array}{l}\text { Фабрика } \\
\text { «Дагюн» }\end{array}$ & 253 & $\begin{array}{c}164 \\
64,8 \%\end{array}$ & 164 & 113 & 65 & 50 \\
\hline Кожзавод & 484 & $\begin{array}{c}286 \\
59,1 \%\end{array}$ & 251 & 137 & 56 & 48 \\
\hline $\begin{array}{l}\text { Швейная } \\
\text { фабрика }\end{array}$ & 243 & $\begin{array}{c}199 \\
81,9 \%\end{array}$ & 105 & 90 & 43,2 & 45,3 \\
\hline $\begin{array}{l}\text { Дербентский } \\
\text { пункт }\end{array}$ & 42 & $\begin{array}{c}32 \\
76,2 \% \\
\end{array}$ & 11 & 10 & 26,2 & 1,2 \\
\hline $\begin{array}{l}\text { Мастерская } \\
\text { инвалидпо- } \\
\text { мощи }\end{array}$ & 60 & $\begin{array}{c}52 \\
86,6 \%\end{array}$ & 16 & 15 & 26,7 & 29 \\
\hline Всего & 2965 & $\begin{array}{c}1872 \\
63,1 \%\end{array}$ & $\begin{array}{c}1572 \\
53,0 \%\end{array}$ & 787 & 51 & 42 \\
\hline
\end{tabular}

Из таблицы видно, что на предприятиях легкой промышленности Дагестана число работающих до начала войны составило 2965 человек, из них рабочих - 1872 , или 63,1\%. Представители коренных национальностей составили 1572 человека, или $53,0 \%$.

Наркомат легкой промышленности ДАССР по характеру производства объединял предприятия двух федеральных наркоматов: предприятия, входящие в наркомат текстильной промышленности (хлопчатобумажная фабрика им. III Интернационала и шерстопрядильная фабрика «Дагюн»), и предприятия, входящие в наркомат легкой промышленности (кожобувной комбинат и Госшвейфабрика). Все предприятия в основном были механизированы, за исключением Госшвейфабрики, механизацию которой начали в 1939 году.

Общий объем производства по наркомату в ценах 1926/27 года на 1939 год составлял 13462 тыс. руб., а фактическое выполнение продукции за 1939 год было определено в сумме 12 093,2 тыс. руб., или 89,8 \%; по предприятиям текстильной промышленности план был выполнен на 81,9\%, а по предприятиям легкой промышленности на 104,7 \%. Как мы видим, план по наркомату в целом не был выполнен из-за предприятий текстильной промышленности [2].

Если сопоставить выпуск продукции в 1939 году с 1937-1938 годами, то видно, что объем выпуска продукции по наркомату возрастает: по сравнению с 1937 годом рост за 1938 год составил 3 147,2 тыс. руб., или 135,2 \%, по сравнению с 1938 годом - 
Гусейнов М.Ш., Гусейнова С.К. Легкая промышленность Дагестана накануне Великой Отечественной войны (1938-1941 гг.)

879,2 тыс. руб., или плюс 7,8 \%. Лучше всего развивалась легкой промышленности: предприятия увеличили выпуск продукции в 1939 году по сравнению с 1937 годом на 75,7 \% и по сравнению с 1938 годом на 28,9 \%. Рост объема продукции по сравнению с 1937 годом составил 2 093,5 тыс. руб. и по сравнению с 1938 годом на 1 090,5 тыс. руб. [3, л. 1-2].

В работе легкой промышленности имелся и ряд недостатков, в том числе частая смена инженерно-технических руководителей и директоров на всех предприятиях, за исключением Госшвейфабрики. Например, на фабрике им. III Интернационала в течение трех лет сменились четыре директора и три главных инженера, на кожобувном комбинате - четыре директора и пять главных инженеров, в Дагюне три директора и четыре главных инженера. На предприятиях была текучесть рабочей силы и большое количество простоев, которые в 1937 году по наркомату составили 64,4 \%, за 1938 год 59,6 \% и за 1939 год - 81,2 \%. В 1939 году количество уволенных составило 1501 чел., в том числе по Постановлению СНК СССР, ЦК ВКП (б) и ВНСПС от 28 декабря 1938 года за нарушение трудовой дисциплины (прогулы) был уволен 1071 чел., в том числе на фабрике им. III Интернационала - 496 чел., на фабрике «Дагюн» - 180 чел., на кожобувном комбинате - 280 чел. и на Госшвейфабрике - 115 чел. [3, л. 3-5].

Общее количество рабочих по Наркомату легкой промышленности в 1939 году составляло 1849 чел. при плане 1946 чел. (95\%). По сравнению с 1937 годом число рабочих увеличилось на 8,3\%, а по сравнению с 1938 годом уменьшилось на 6,5\%. Уменьшение числа рабочих объяснялось переходом на двухсменную работу на фабрике им. III Интернационала и механизацией Госшвейфабрики. Среднегодовая выработка одного рабочего в 1939 году по сравнению с 1937 годом выросла на 24,3 \% и с 1938 годом - на 11,2 \%. Среднегодовая зарплата в 1939 году по сравнению с 1937 годом выросла на $106 \%$ [4, с. 6].

Предприятия легкой и текстильной промышленности Дагестанской АССР выполнили план 1940 года на 90,8 \%, в том числе по текстильной промышленности - на 91,4 \% и легкой - на 89,9\%.

Работа отдельных отраслей характеризуется следующими данными [5, л. 68]:

\begin{tabular}{|l|c|c|c|}
\hline \multicolumn{1}{|c|}{ Предприятия } & План на 1940 г. & $\begin{array}{c}\text { Фактически } \\
\text { выполнено за год }\end{array}$ & \% \\
\hline Фабрика им. ІІІ Интернационала & 4500 & 4510,1 & 100,2 \\
\hline Фабрика «Дагюн» & 3811 & 2187,5 & 79,9 \\
\hline Кожобувная фабрика & 2736 & 2187,5 & 79,9 \\
\hline Швейная фабрика & 2464 & 2491,7 & 101,1 \\
\hline $\begin{array}{l}\text { Итого по наркомату легкой про- } \\
\text { мышленности }\end{array}$ & 13512 & 12275,8 & 90,8 \\
\hline
\end{tabular}

Как видно из приведенных данных, план по наркомату не был выполнен в результате неудовлетворительной работы шерстопрядильной фабрики «Дагюн» и кожобувного комбината.

На фабрике «Дагюн» основными причинами того, что план не был выполнен были: низкая производительность труда, неналаженность технологического процесса, сверхплановый простой оборудования, слабая трудовая дисциплина, а также неудовлетворительное снабжение сырьем (шерстью). 
Гусейнов М.Ш., Гусейнова С.К. Легкая промышленность Дагестана накануне Великой Отечественной войны (1938-1941 гг.)

Невыполнение плана по кожобувному комбинату также стало следствием недостаточного снабжения сырьем. В течение года комбинат недополучил 53 т сырья при плановой потребности предприятия в 136 т. 26 июня 1940 года в связи с обострением международной обстановки Президиум Верховного Совета СССР издал указ об удлинении рабочего дня и введении семичасовой рабочей недели. Трудящиеся страны отнеслись к этому решению с пониманием. Многие рабочие достигли показательных результатов на своем участке. Например, на фабрике им. III Интернационала ткачиха Мария Рубцова, работающая на четырех станках, в июле выработала 3396 метров бязи, а в сентябре - 3852 метра, т. е. увеличила выпуск продукции на 13,4 \% (на 456 метров). Солодовникова Дарья - ткачиха, работающая на шести станках, в июне месяце выработала 3 164,8 метров бязи при норме 2 981,5 метров, а в ноябре - 4288 метров при норме 3 494,6 метров, т. е. фактически увеличила выработку на 1124 метра или на $35,5 \%$ [5, л. 68-74].

На кожобувном комбинате Гребникова Алла, работая на строчке обуви, при дневной норме до указа Президиума Верховного Совета СССР выпускала 210 пар, в июле того же года прострочила 275 пар, в сентябре при норме 240 пар выпустила 290 пар, в ноябре - 350 пар [5, л. 68-74].

Таким образом, трудящиеся легкой промышленности Дагестана, следуя Указу Президиума Верховного Совета СССР от 26 июня 1940 года, успешно выполняли и перевыполняли производственные планы по выпуску продукции.

На фабрике им. III Интернационала за первый квартал 1940 г. было внесено 16 рацпредложений, из них 6 внедрено в производство. Благодаря четырем предложениям в год получили экономию 5078 руб.

Рацпредложения поступали от инженера Апполонова, который стал использовать утонченный ватерный шнур. Вместо 12 нитей шнур стали готовить из 6. Это предложение дало в год экономию в 34182 руб. Гаврилов - помощник мастера ткацкого цеха заменил у ремизоподъемного механизма на ткацком станке чугунные подшипники деревянными, что давало экономию в год 1610 руб. Благодаря деревянным подшипниками нити стали меньше рваться.

Мастер по ремонту Муталимов и слесарь Мустафаев предложили реставрировать старые челноки, что давало экономию свыше 1000 руб. в год. Рацпредложения вносили также инженеры Лукьянов, Эльдарушев, Волков и др. Главный механик Курганский и зав. электроотделом Гулянко изобрели новый станок, который оплетал старые перегоревшие электрические провода, что также давало значительную экономию [6, л. 76].

Наркомат легкой промышленности и его предприятия в первом полугодии 1941 года из месяца в месяц выполняли свои производственные программы. Успешнее всего работала фабрика им. III Интернационала. Наркомат добился снижения себестоимости по всем предприятиям до 5,5 \% вместо плана 2,2 \%, повысилось качество готовой продукции и увеличился выпуск продукции первых сортов. План накопления перевыполнили на 211,4 тыс. руб., дали накопления - 4 805,4 тыс. руб., вместо установленного по плану - 4594 тыс. руб.

План по выпуску валовой продукции был выполнен на 94,7 \%, в том числе по текстильной промышленности на 102,3 \% и легкой промышленности - на 84,2 \%. Выполнение плана по отдельным предприятиям составило:

- фабрика им. III Интернационала - на 104,4 \%

- фабрика «Дагюн» - на 98,6 \%

- Госшвейфабрика - на 100,7 \% 
Гусейнов М.Ш., Гусейнова С.К. Легкая промышленность Дагестана накануне Великой Отечественной войны (1938-1941 гг.)

- Буйнакский кожобувной комбинат - на 67 \% [7, л. 98].

Наркомат легкой промышленности в первом полугодии 1941 года недодал шерстяной пряжи на 20 тыс. руб. и обуви на 475 тыс. руб. Был произведен перерасход по фонду заработной платы в сумме 269,5 тыс. руб., что составляло 9,1 \% от всего фонда.

Средняя зарплата рабочих выросла на 3,7 \%. СНК ДАССР признал работу предприятий легкой промышленности за первое полугодие 1941 г. неудовлетворительной и обязал наркома легкой промышленности ДАССР Михайлова обеспечить контроль за исполнением распоряжений Совнаркома ДАССР и приказов наркоматов РСФСР, направленных на улучшение работы предприятий.

Началась Великая Отечественная война. Работники предприятий легкой промышленности с удвоенными усилиями трудились на своих предприятиях. Широко развернулось стахановское движение. Многие работницы фабрики им. III Интернационала нормы выпуска продукции выполняли на 107-112\%. Девять ткачих фабрики с 4-х станков перешли на работу на 6-ти станках $[4$, с. 11$]$.

Госшвейфабрика выполнила план по выпуску валовой продукции за первое полугодие на 100,7\%. Тем не менее, по отдельным видам изделий он остался не выполнен. Так, в первое полугодие 1941 г. планировалось выпустить 800 шт. зимних мужских пальто с воротником, а фактически выпустили 436 шт., или всего $55 \%$, демисезонных пальто - 1200 шт. (выпустили 824), или 68,6 \%, гимнастерок - 1 500, (430, или 28,6 \%) [7, л. 106].

Выполнить план по зимним пальто фабрика могла, материала было достаточно, но меховые воротники были получены только во втором квартале 1941 года.

В работе фабрики наметилась положительная динамика - повысились качество выпускаемых швейных изделий и их сортность. По плану было предусмотрено выпустить 90,5\% продукции 1-го сорта, фактически было выпущено- 92,3 \% и т. д.

Шерстопрядильная фабрика «Дагюн» за первое полугодие 1941 года выполнила план на 98,6 \%. Невыполнение плана выпуска пряжи по ассортименту объяснялось неудовлетворительным снабжением фабрики шерстью, особенно в I квартале (январь, февраль), а также неудовлетворительной организацией производства, отступлением от технологии обработки шерсти, что привело к недостаточному использованию агрегатов и станков. Качество выпускаемой пряжи было удовлетворительным, отвечающим стандарту. Несмотря на невыполнение плана по выпуску себестоимость продукции фабрики снизилась на $6,8 \%$, в сравнении с прошлым годом, а в сравнении с планом - на 5,3\%, благодаря чему за 6 месяцев было накоплено 955,4 тыс. руб., в т. ч. сверх плана - 190,4 тыс. руб. [7, л. 109].

Буйнакский кожобувной комбинат за первое полугодие 1941 года выполнил план на $67 \%$. Недовыполнение плана по комбинату явилось следствием недоснабжения Главкожуправлением обувной промышленности: из положенных по плану 77,2 т комбинат получил 57,8 т, и только во втором квартале.

Неоднократные обращения в центральные органы по вопросу упорядочения снабжения Буйнакского кожобувного комбината в течение первого полугодия не дали существенных результатов, и два распоряжения СНК РСФСР и Наркомлегкомпрома РСФСР об обеспечении бесперебойной работы Буйнакского кожобувного комбината остались невыполненными.

Отсутствие кожи для подошв вынудило комбинат перейти на изготовление обуви с резиновой подошвой, т. е. более дешевой. Это сказалось на выполнении плана. 
Гусейнов М.Ш., Гусейнова С.К. Легкая промышленность Дагестана накануне Великой Отечественной войны (1938-1941 гг.)

Мобилизуя трудящихся на выполнение третьей пятилетки, хозяйственные организации стали более активно заниматься решением насущных вопросов, связанных с производством, подбором и расстановкой кадров, рациональным использованием техники, укреплением трудовой дисциплины, улучшением условий труда и жизни рабочих и ИТР. Контролируя деятельность администрации предприятий, они добивались повышения ответственности хозяйственных и инженерно-технических работников за претворение в жизнь директив партии и правительства.

Неоценимую поддержку в развитии промышленности Дагестана и подготовке квалифицированных кадров для республики оказывали трудящиеся Российской Федерации и других республик СССР. Из крупных индустриальных центров страны в Дагестан прибывало оборудование, приезжали рабочие, инженеры и техники, с помощью которых местные жители осваивали сложную технику и приобретали высокую квалификацию. Одновременно тысячи рабочих Дагестана овладевали новой техникой, накапливали производственный опыт на крупнейших предприятиях страны. В 1939 г. бригады рабочих фабрики им. III Интернационала побывали на предприятиях Калининского хлопчатобумажного комбината с целью ознакомления с опытом работы [8, c. 313].

Продукция, изготовленная на фабрике им. III Интернационала, отправлялась в Москву, Ленинград и многие другие промышленные центры страны. Успехи трудящихся Дагестана, достигнутые в годы довоенных пятилеток в индустриальном развитии республики были завоеваны благодаря помощи народов Российской Федерации и союзных республик.

\section{Литература}

1. Центральный государственный архив Республики Дагестан (далее ЦГА РД). Ф. 1-п. Оп. 1. Д. 4107.

2. Гусейнов М.Ш. Фабрично-заводская промышленность Дагестана накануне Великой Отечественной войны 1941-1945 гг. // Вестник ДГУ. - 2019. - Вып. 1.

3. ЦГА РФ. Ф. 1-п. Оп. 1. Д. 4838.

4. Салихова Л.Б. Фабрично-заводская промышленность Дагестана. Конец XIX нач. ХХ в. // Известия СОИГСИ. - 2018. - № 1/3.

5. ЦГА РД. Ф. 168-р. Оп. 20. Д. 120.

6. ЦГА РД. Ф. 1-п. ОП. 1. Д. 4835.

7. ЦГА РД. Ф. 168-р. Оп. 21. Д. 40.

8. Амирханова М.M. Организация труда в промышленности Дагестана в 30-е гг. ХХ в. // Известия СОИГСИ. - 2018. - № 1/10.

9. Гусейнов М.Ш. Выравнивание уровня экономического развития автономных республик и областей юго-востока России в составе Северо-Кавказского края // Вестник ДГУ. - 2017. - Т. 32, вып. 1.

10. Суздальцева И.А. О роли русских переселенцев в развитии новых отраслей экономики Дагестана (вторая половина XIX - начало XX в.) // Вестник ДГУ. Сер.: Гуманитарные науки. - 2014. - Вып. 2. - С. 39-44.

Поступила в редакиฺию 13 апреля 2019 г. 
Гусейнов М.Ш., Гусейнова С.К. Легкая промышленность Дагестана накануне Великой Отечественной войны (1938-1941 гг.)

UDC 967

DOI: $10.21779 / 2542-0313-2019-34-2-7-13$

Light industry of Dagestan on the eve of the great Patriotic war (1938-1941)

\author{
M.Sh. Huseynov ${ }^{1}$, S.K. Huseynova ${ }^{2}$ \\ ${ }^{1}$ Dagestan State University; Russia, 367001, Makhachkala, M. Gadzhiev st., 43a; dek- \\ anif@mail.ru \\ ${ }^{2}$ MBOU secondary school № 10 of Makhachkala; Russia, Makhachkala, Yu. Akaev st., \\ 69; ege200610@yandex.ru
}

The article is devoted to the invaluable contribution of the peoples of the Russian Federation and other peoples of the USSR to the development of new branches of light industry in Dagestan on the eve of the great Patriotic war. Considerable work has been done on the workers' and engineer indigenization and the attraction of mountain women in light industry, mechanization of light industry enterprises, improvement of the social conditions of the workers.

The light industry enterprises improved both production indicators and their quality yearly. There were some shortcomings observed in the work of light industry, to be exact - frequent change of engineering staff and directors. The given period can be characterized by the increase of the wages among workers, engineers and employees. On the eve of the war, the workforce of the Dagestan enterprises achieved good results in their area.

Keywords: Russian Federation, Dagestan, people's Commissariat, light industry, the eve of the great Patriotic war, planning.

Received 13 April, 2019 